\title{
Upaya Peningkatan Kunjungan Posyandu Citra di Desa Jayaraga Tarogong Kidul Garut
}

\author{
Udin Rosidin', Theresia Eriyani², Ahmad Yamin $^{3}$ \\ Universitas Padjadjaran, \\ Jl. Raya Bandung - Sumedang No.KM. 21, Hegarmanah, Kec. Jatinangor, Kabupaten Sumedang, \\ Jawa Barat $45363^{1,2,3}$ \\ Email: udin.rosidin@unpad.ac.id ${ }^{1}$
}

\begin{abstract}
ABSTRAK
Kegiatan PPM ini dilatarbelakangi dengan adanya penurunan kunjungan posyandu pada enam bulan terakhir rata rata sebanyak 49,3\%. Menurut hasil survey yang dilakukan oleh mahasiswa Program Bina Desa menunjukkan bahwa rata rata pengetahuan dan motivasi masyarakat tentang posyandu sangat kurang. Memperhatikan hal tersebut penulis mengadakan musyawarah dengan Kepala Puskesmas Haurpanggung, Kepala Desa Jayaraga, Ketua RW dan RT serta kader kesehatan. Dari pembahasan tersebut disepakati bahwa diperlukan beberapa kegiatan untuk mengatasi permasalahan tersebut. Tujuan pengabdian masyarakat adalah melakukan kegiatan yang dapat meningkatkan kunjungan masyarakat di posyandu. Metode yang digunakan untuk mencapai tujuan adalah pelaksanaan pendidikan kesehatan tentang posyandu, pemberian makanan tambahan dan pemeriksaan kesehatan serta melaksanakan olah raga bersama masyarakat di posyandu. Dampak dari kegatan tersebut belum bisa diukur dengan maksimal karena kunjungan posyandu pada masa pandemi covid 19 tidak setiap bulan dilaksanakan. Evaluasi pada bulan Juli 2020 didapatkan data kunjungan posyandu sebesar 77,1 \% sehingga ada peningkatan kunjungan sebesar 27,8 \%. Kesimpulan dari kegiatan pengabdian ini adalah adanya peningkatan kunjungan masyarakat ke Posyandu Citra Desa Jayaraga Kecamatan Tarogong Kidul Kabupaten Garut.
\end{abstract}

Kata Kunci : Peningkatan Kunjungan; Posyandu; Upaya

\begin{abstract}
This PPM activity was motivated by a decrease in posyandu visits in the last six months by an average of 49.3\%. According to the results of a survey conducted by the Bina Desa program students, it was shown that the average community knowledge and motivation about posyandu was very low. Noting this, the authors held deliberations with the Head of the Haurpanggung Health Center, the Head of Jayaraga Village, the Head of $R W$ and RT, and health cadres. From the discussion, it was agreed that several activities were needed to overcome these problems. The purpose of community service is to carry out activities that can increase community visits at the posyandu. The method used to achieve this goal is the implementation of health education about posyandu, providing additional food and health checks, and carrying out sports with the community at the posyandu. The impact of these activities cannot be measured maximally because posyandu visits during the Covid 19 pandemic were not carried out every month. Evaluation in July 2020 obtained data on posyandu visits of $77.1 \%$, so there was an increase in visits by $27.8 \%$. The conclusion of this service activity is an increase in community visits to Posyandu Citra, Jayaraga Village, Tarogong Kidul District, Garut Regency.
\end{abstract}

Keywords: Increased Visits; Posyandu; Effort

Upaya Peningkatan Kunjungan, Udin Rosidin | 243 


\section{PENDAHULUAN}

Pandangan masyarakat tentang kesehatan terus berkembang sesuai dengan kemajuan ilmu pengetahuan dan teknologi. Saat ini paradigma sehat merupakan pandangan masyarakat yang terus diperhatikan dan sejalan dengan tujuan dari Program Pemerintah yang telah dicanangkan dalam Peraturan Menteri Kesehatan Republik Indonesia Nomor 38 Tahun 2016 Tentang Pedoman Penyelenggaraan Program Indonesia Sehat dengan Pendekatan Keluarga. Masyarakat yang sehat adalah masyarakat yang ikut serta dalam rangka penyelenggaraan Program Indonesia Sehat yang terdiri dari 12 Indikator utama yaitu; 1) Keluarga Mengikuti Proram Keluarga Berencana (KB); 2) Ibu Melakukan Persalinan di Fasilitas Kesehatan; 3) Bayi Mendapat Imunisai dasar lengkap; 4) Bayi mendapat Air Susu Ibu (ASI) eksklusif; 5) Balita mendapatkan pemantauan pertumbuhan; 6) Penderita TB Paru mendapatkan pengobatan sesuai standar; 7) Penderita hipertensi melakukan pengobatan secara teratur 8) Penderita gangguan jiwa mendapatkan pengobatan dan tidak diterlantarkan 9) Anggota keluarga tidak ada yang merokok; 10) Keluarga sudah menjadi anggota Jaminan Kesehatan Nasional (JKN); 11) Keluarga mempunyai akses sarana air bersih; dan 12) Keluarga mempunyai akses atau menggunakan jamban sehat (Kemenkes, 2016).

Untuk mencapai masyarakat sehat dengan melaksanakan 12 indikator tersebut perlu keterlibatan berbagai pihak seperti pemerintah, swasta dan masyarakat. Masyarakat sehat akan terwujud apabila seluruh masyarakat turut serta berpartisipasi dalam upaya melaksanakan indikator tersebut. Pemerintah khususnya sektor kesehatan melalui berbagai program sudah banyak melakukan pembinaan kepada masyarakat agar ikut partisipasi dalam melaksanakan hidup sehat. Salah satu program kesehatan yang dilaksanakan yaitu program Upaya Kesehatan bersumber daya masyarakat (UKBM) (Pranata et al, 2011).

Program UKBM bertujuan agar masyarakat mampu mengatasi permasalahan kesehatan yang dihadapi secara mandiri melalui pembinaan pemberdayaan masyarakat bidang kesehatan yang terintegrasi dan bersinergi dengan instansi terkait. Program UKBM yang paling depan dalam pelayanan kesehatan yaitu pelayanan posyandu. Dengan adanya program posyandu maka tujuan pemerintah untuk menjadikan masyarakat sehat sangat berpeluang, karena dengan adanya posyandu partisipasi masyarakat akan meningkat. Selain itu dengan adanya posyandu masyarakat menjadi lebih mudah mengakses pelayanan kesehatan karena jarak yang dekat dengan lingkungan tempat tinggalnya (Depkes, 2009)

Posyandu merupakan salah satu bentuk upaya kesehatan bersumber daya masyarakat yang dikelola dan diselenggarakan dari, oleh, untuk dan bersama masyarakat. Posyandu 
dapat memberikan kemudahan kepada masyarakat dalam memperoleh pelayanan kesehatan dasar. Posyandu merupakan sistem pelayanan kesehatan yang berbasis masyarakat, dilakukan secara efektif dan efisien dan dapat menjangkau semua sasaran yang membutuhkan layanan tumbuh kembang anak, ibu hamil, ibu menyusui, dan ibu nifas. Posyandu menjadi tanggung jawab seluruh komponen bangsa dalam menyediakan fasilitas dan menyelenggarakan upaya kesehatan. Strategi pendekatan upaya kesehatan bersumber daya masyarakat adalah dengan akses sosial budaya masyarakat yang didasarkan atas nilainilai tradisi gotong royong sehingga masyarakat mandiri dalam mengatasi masalaah kesehataannya (Malinda, 2018)

Desa Jayaraga merupakan salah satu desa yang sering menjadi daerah binaan mahasiswa dan dosen Unpad. Berbagai kegiatan dilaksanakan dengan melibatkan masyarakat dari berbagai kelompok usia. Desa Jayaraga memiliki posyandu yang dibina oleh instansi lain sebagai mitra,. Posyandu tersebut adalah posyandu Citra yang berlokasi di RT 04 RW 12. Posyandu Citra merupakan posyandu bentukan PPM dosen Unpad yang diresmikan pada bulan Oktober 2018. Dalam pengelolaannya Posyandu Citra memiliki mitra yaitu Dharma Wanita Pusat Unpad dan Puskesmas Haurpanggung. Berdasarkan evaluasi selama enam bulan terakhir pelayanan Posyandu Citra ditemukan rata rata kunjungan ke posyandu sebesar 49,3\%. Data survey mahasiswa BEM Keperawatan Unpad Kampus Garut dalam kegiatan pengabdian masyarakat, didapatkan bahwa tidak seluruhnya bayi dan balita datang ke posyandu. Pengetahuan masyarakat tentang manfaat posyandu sebanyak 54,2\% memiliki pengetahuan yang kurang. Untuk nilai motivasi $41,7 \%$ responden kurang motivasinya terhadap posyandu. Sikap ibu untuk membantu posyandu juga kurang sebanyak $58,3 \%$. Ibu yang mengatakan tidak bersedia untuk membantu posyandu sebanyak $70,8 \% \mathrm{ibu}$ yang mengatakan tidak siap untuk membantu dana posyandu dan sikap ibu untuk jadi kader posyandu pun kurang yaitu sebanyak 79,2\%. Keluarga yang mempunyai bayi dan balita merasa malas dan enggan untuk mengikuti posyandu. Upaya untuk mengajak mereka datang ke posyandu selalu diupayakan melalui pengumuman dan surat pemberitahuan dari RW (Rosidin et al, 2020).

Berdasarkan permasalahan tersebut diatas dapat dianalisis bahwa faktor yang menjadi penyebab rendahnya kunjungan masyarakat ke posyandu adalah kurangnya pengetahuan masyarakat tentang manfaat posyandu, kurangmya motivasi masyarakat untuk datang dan berpartisipasi dalam kegiatan posyandu. Apabila kondisi permasalahan tersebut dibiarkan maka dipastikan kunjungan posyandu akan semakin menurun. Pertumbuhan dan 
perkembangan anak tidak akan terkontrol dan dimungkinkan masalah kesehatan lain akan timbul.

Upaya untuk mengatasi permasalahan tersebut diatas perlu dilakukan kegiatan pembinaan yang bertujuan untuk peningkatan kunjungan masyarakat ke posyandu. Kegiatan yang dilakukan harus sesuai dengan akar masalah rendahnya kunjungan masyarakat ke posyandu. Berdasarkan survey yang dilakukan maka pembinaan harus difokuskan kepada peningkatan pengetahuan masyarakat melalui pendidikan kesehatan, peningkatan motivasi masyarakat melalui kegiatan posyandu yang menarik serta perlu melakukan kegiatan bersama masyarakat untuk peduli kepada masalah kesehatan yang ada disekitarnya. Dengan meningkatnya pengetahuan, motivasi dan keterlibatan masyarakat dalam kegiatan posyandu maka diharapkan masyarakat akan selalu datang ke posyandu yang pada akhirnya akan berdampak pada meningkatkan kunjungan posyandu.

\section{METODE}

Sebelum kegiatan PPM dilaksanakan, penulis terlebih dahulu melaksanakan pendekatan sosial dengan mengadakan pertemuan dengan Kepala Puskesmas Haurpanggung, Kepala Desa Jayaraga dan kader kesehatan. Pertemuan membahas permasalahan yang dimungkinkan menjadi penyebab rendahnya kunjungan masyarakat ke posyandu. Dalam pendekatan sosial disepakati hal hal yang dimungkinkan dapat meningkatkan kunjungan masyarakat ke posyandu. Kegiatan yang disepakati yaitu kegiatan pendidikan kesehatan untuk meningkatkan pengetahuan masyarakat tentang posyandu, memberikan makanan tambahan dan pemeriksaan kesehatan sebagai upaya untuk meningkatkan motivasi masyarakat berkunjung ke posyandu dan melaksanakan kegiatan bersama masyarakat di posyandu. Dalam pelaksanaan upaya peningkatan kunjungan ke posyandu tim PPM bekerja sama dengan Dharma Wanita Unpad dan program Bina Desa dari BEM Fakultas Keperawatan Unpad.

\section{HASIL, PEMBAHASAN DAN DAMPAK}

Kegiatan yang dilaksanakan sebagai upaya peningkatan kunjungan masyarakat ke Posyandu Citra sebagai hasil kesepakatan adalah melakukan kegiatan pendidikan kesehatan untuk meningkatkan pengetahuan masyarakat, melakukan pemeriksaan kesehatan dan pemberian makanan tambahan untuk meningkatkan motivasi masyarakat datang ke posyandu serta melaksanakan kegiatan bersama masyarakat. Kegiatan tersebut tidak bisa dilaksanakan setiap bulan karena pandemi covid 19 berdampak pada seluruh kegiatan di 
masyarakat. Diberlakukannya pembatasan sosial berdampak pula pada kegiatan posyandu di Desa Jayaraga. Posyandu Citra tidak setiap bulan bisa dilaksanakan sehingga evaluasi kegiatan hanya dilihat dari satu bulan saja yaitu bulan Juli 2020 dengan kunjungan sebanyak 77,1 \% . Apabila dilihat dari rata rata kunjungan di Posyandu Citra pada enam bulan terakhir yaitu sebanyak 49,1 \% maka dampak dari kegiatan PPM ini ada kenaikan sekitar 27,8 \%.

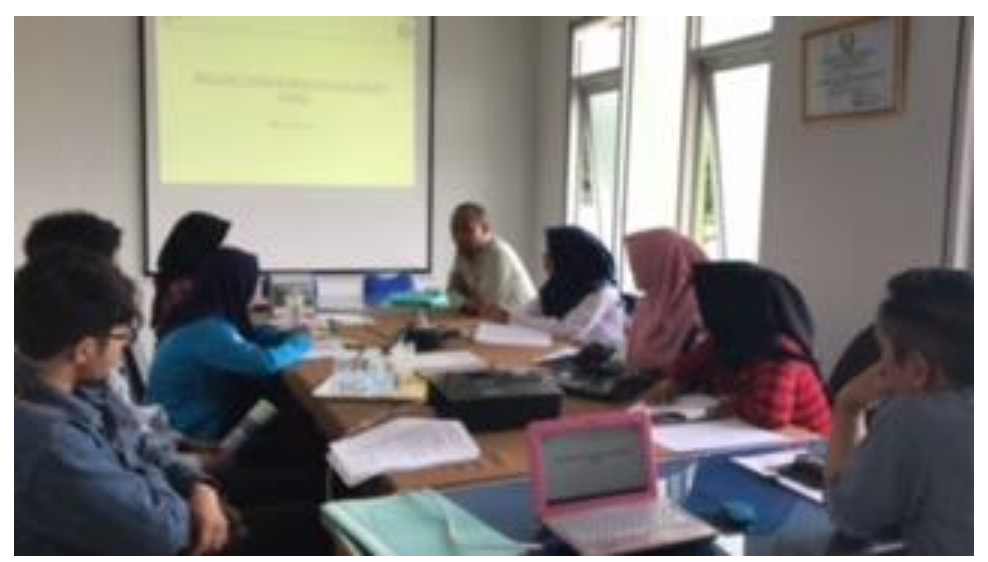

Gambar 1 Suasana pendekatan sosial untuk merencanakan kegiatan PPM

Karena pada saat sedang dilakukan pembinaan terjadi himbauan pemerintah untuk pembatasan sosial (PSBB). Kondisi tersebut sangat berdampak pada kunjungan masyarakat ke Posyandu Citra. Pelayanan Posyandu Citra tidak dilaksanakan setiap bulan dan dihentikan sementara selama tiga bulan, yaitu bulan Maret, April dan Mei. Mulai bulan Juni atas kesepakatan dengan pemerintah daerah dan puskesmas maka pelayanan posyandu mulai dibuka.

Peningkatan kunjungan masyarakat ke Posyandu Citra dimungkinkan terjadi adanya peningkatan pengetahuan dan motivasi masyarakat untuk datang ke posyandu. Pendidikan kesehatan dilaksanakan setiap bulan sebelum pelayanan kesehatan di Posyadu Citra di laksanakan. Pendidikan kesehatan yang dilaksanakan secara rutin dapat meningkatkan pengetahuan seseorang (Suhendar et al, 2020). Pendidikan kesehatan yang dilaksanakan pada pengabdian ini adalah menyampaikan materi tentang manfaat posyandu. Dengan materi tersebut diharapkan masyarakat mendapatkan informasi dan pemahaman yang baik tentang posyandu sehingga akan berdampak positif terhadap kunjungan masyarakat ke posyandu. Apabila masyarakat secara maksimal memanfaatkan keberadaan posyandu maka dipastikan masyarakat akan selalu memperhatikan kesehatannya. Posyandu merupakan salah satu pelayanan kesehatan di RW untuk memudahkan masyarakat mengetahui atau memeriksakan kesehatan terutama untuk ibu hamil dan anak balita (Widyaningsih et al, 2020). 
Dalam pelaksanaannya pendidikan kesehatan yang dilaksanakan selain berdampak pada peningkatan pengetahuan masyarakat juga akan berdampak pula pada kemampuan masyarakat dalam mengatasi masalah kesehatannya. Secara umum salah satu tujuan penyelenggaraan posyandu meningkatkan kemampuan masyarakat untuk mengembangkan kegiatan kesehatan dan kegiatan lain yang menunjang sesuai kebutuhan (Saragih, 2011).

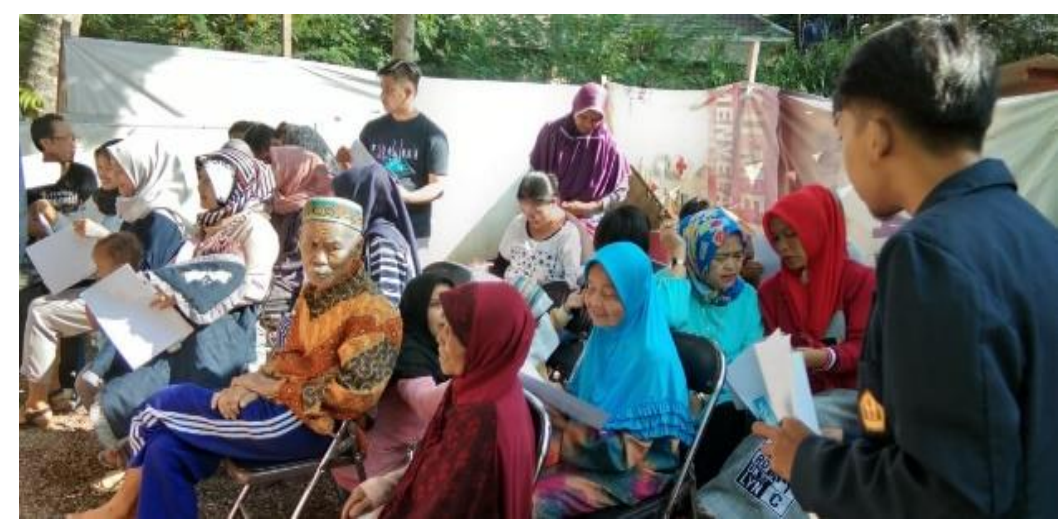

Gambar 2 Suasana kegiatan pendidikan kesehatan

Kegiatan lain yang dilakukan untuk meningkatkan kunjungan masyarakat ke Posyandu Citra adalah memberikan PMT yang menarik dan pemeriksaan kesehatan. Pemberian makanan tambahan dan pemeriksaan kesehatan dilaksanakan setiap bulan pada waktu pelayanan Posyandu Citra dibuka. PMT diberikan kepada seluruh pengunjung posyandu sebagai daya tarik. Sedangkan pemeriksaan kesehatan hanya dilakukan kepada pengunjung posyandu dewasa. Pemberian makanan tambahan dan pemeriksaan kesehatan kepada pengunjung posyandu merupakan upaya untuk meningkatkan motivasi masyarakat. Dengan motivasi yang baik maka seseorang akan melaksanakan kegiatan tanpa paksaan dari siapapun. Motivasi dapat menyebabkan seseorang atau kelompok orang tergerak untuk datang ke posyandu karena ingin mendapatkan PMT atau diperiksa kesehatannya. Menurut hasil penelitian (Suryaningsih, 2012), didapatkan ada hubungan yang bermakna antara motivasi dengan perilaku kunjungan ibu bayi ke posyandu.
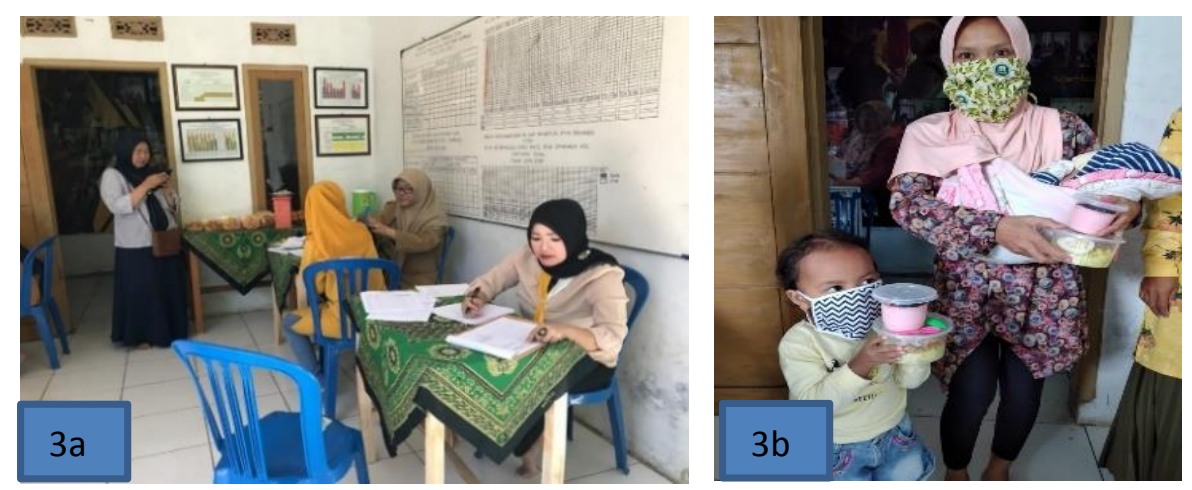

Gambar 3a. Pemeriksaan kesehatan pada Lansia, Gambar 3b. Pemberian makanan tambahan 
Sesuai dengan konsep posyandu bahwa dalam penyelenggaraan posyandu pada prinsipnya memberdayakan masyarakat dan memberikan kemudahan kepada masyarakat dalam memperoleh pelayanan kesehatan dasar sehingga meningkatkan daya jangkau pelayanan kesehatan (Ocbrianto, 2012). Prinsip memberdayakan masyarakat adalah peluang untuk menjadikan posyandu sebagai pusat kegiatan masyarakat. Dalam pelaksanaannya posyandu bukan saja sebagai tempat pelayanan kesehatan tetapi posyandu juga merupakan pusat kegiatan masyarakat untuk tukar pendapat dan pengalaman serta bermusyawarah untuk memecahkan masalah kesehatan yang dihadapi masyarakat (Kusumadinata, 2014).

Memperhatikan hal tersebut maka semua kegiatan masyarakat harus dipusatkan di posyandu. Olah raga yang dilakukan bersama masyarakat oleh tim PPM diharapkan menjadi motivasi untuk meningkatkan kunjungan dan mengaktifkan posyandu. Senam bersama yang dilakukan seminggu sekali dapat dijadikan media bagi masyarakat untuk berdiskusi, tukar informasi dan bermusyawarah memecahkan masalah kesehatan. Apabila semua kegiatan masyarakat sudah terfokus di posyandu maka program pemberdayaan masyarakat akan semakin nyata. Menurut (Kusumadinata, 2014) fungsi posyandu yaitu sebagai wadah pemberdayaan masyarakat dalam alih informasi dan keterampilan dari petugas kepada masyarakat dan antar sesama masyarakat.

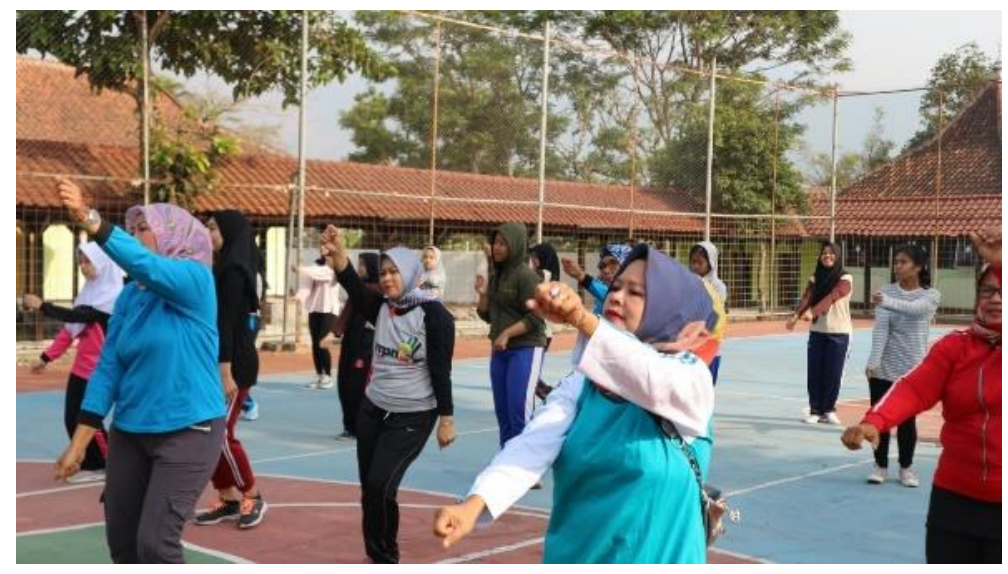

Gambar 4 Suasana kegiatan oleh raga bersama

Semua upaya yang dilakukan oleh tim PPM bertujuan agar masyarakat dapat meningkatkan kunjungan untuk pemanfaatan posyandu. Peningkatan pengetahuan, motivasi dan aktif melakukan kegiatan di posyandu akan menjadi modal awal masyarakat untuk mau berkunjung ke posyandu. Apalagi ibu ibu yang memiliki anak balita di Posyandu Citra sebagian besar merupakan keluarga yang baru memiliki anak. Ibu yang baru memiliki anak akan lebih memperhatikan kesehatan anaknya sehingga akan memiliki kepatuhan untuk datang ke Posyandu. Menurut (Pangesti \& Agussafutri, 2019), bahwa pada ibu yang berumur muda dan baru memiliki anak akan cenderung memberikan perhatian yang lebih 
besar terhadap anak mereka, seiring bertambah usia, bertambah kesibukan dan bertambah jumlah anak maka ini akan mempengaruhi motivasi untuk memberikan pelayanan kesehatan yang baik untuk anak.

Banyak faktor yang menyebabkan seseorang datang ke posyandu. Apabila memperhatikan teori Green (Notoatmodjo, 2014) kegiatan pengabdian yang dilakukan oleh tim PPM hanya dari faktor predisposisi. Faktor lain yang dimungkinkan akan mempengaruhi kunjungan ke posyandu diantaranya adalah keterlibatan tokoh masyarakat. Keterlibatan pemimpin informal dan partisipasi masyarakat akan berpengaruh terhadap keberhasilan program posyandu. Berdasarkan hal tersebut kegiatan PPM kedepan sebaiknya difokuskan pula kepada tokoh masyarakat.

\section{SIMPULAN}

Setelah kegiatan pengabdian pada masyarakat di RW 12 Desa Jayaraga dilakukan maka berdampak pada peningkatan kunjungan di Posyandu Citra. Sebelum kegiatan dilaksanakan rata rata kunjungan masyarakat ke Posyandu Citra sebanyak 49,3\% dan setelah dilakukan kegiatan pengabdian naik menjadi 77,1\%, terjadi peningkatan kunjungan sebesar $27,8 \%$. Evaluasi kunjungan setelah dilakukan kegiatan pengabdian tidak diambil dari rata rata kunjungan tapi diambil dari kunjungan bulan terakhir yaitu bulan Juli 2020 karena pada akhir kegiatan pelayanan posyandu terganggu oleh pandemi covid 19. Peningkatan kunjungan masyarkat tersebut merupakan potensi yang baik untuk meningkatkan peran serta masyarakat dalam mengenal dan mengatasi masalah kesehatannya secara mandiri.

\section{UCAPAN TERIMA KASIH}

Ucapan terimakasih penulis sampaikan kepada Rektor Universitas Pajajaran, Dekan Fakultas Keperawatan Universitas Pajajaran, Pengurus Dharma Wanita pusat Universitas Pajajaran, Camat Kecamatan Tarogong Kidul Garut, Kepala Puskesmas Haurpanggung Garut, Kepala Desa Jayaraga Garut, Ketua RW 12 dan Ketua RT di lingkungan RW 12, kader kesehatan pengelola Posyandu Citra dan segenap mahasiswa pelaksana program Bina Desa BEM Fakultas Keperawatan Universitas Pajajaran dan pihak pihak yang sudah membantu kegiatan pengabdian masyarakat. Semoga bantuannya menjadi amal baik dan mendapat balasan dari Allah SWT, Aamiin. 


\section{DAFTAR PUSTAKA}

Depkes, R. I. (2009). Undang-undang Republik Indonesia nomor 36 tahun 2009 tentang Kesehatan. Lembaran Negara Republik Indonesia Nomor, 144.

Kemenkes, R. I. (2016). Pedoman Penyelenggaraan Program Indonesia Sehat dengan Pendekatan Keluarga. Lampiran Peraturan Kementerian Kesehatan, (39).

Kusumadinata, A. (2014). Analisis Model Komunikasi Kelompok Dalam Pemberdayaan Masyarakat (Studi Kasus Pada Pos Pelayanan Terpadu (Posyandu)). Jurnal Sosial Humaniora, 5(1).

Malinda, V. (2018). Implementasi Peraturan Menteri Dalam Negeri Nomor 54 Tahun 2007 Tentang Pedoman Pembentukan Kelompok Kerja Operasional Dalam Rangka Pelaksanaan Fungsi Posyandu Di Dinas Pemberdayaan Masyarakat Dan Desa Kabupaten Deli Serdang.

Notoatmodjo, S. (2014). Kesehatan Masyarakat Ilmu dan Seni, Rineka Cipta. Jakarta.

Ocbrianto, H. (2012). Partisipasi Masyarakat Terhadap Posyandu dalam Upaya Pelayanan Kesehatan Balita. Skripsi Fakultas Ilmu Sosial Dan Ilmu Politik. Universitas Indonesia.

Pangesti, C. B., \& Agussafutri, W. D. (2019). Hubungan Status Pekerjaan dan Pengetahuan Ibu Tentang Posyandu Balita Dengan Kepatuhan Kunjungan Posyandu di Posyandu Balita Singosari Kelurahan Banyuanyar Surakarta Tahun 2018. Jurnal Kebidanan Indonesia: Journal of Indonesia Midwifery, 10(2), 32-40.

Pranata, S., Pratiwi, N. L., \& Rahanto, S. (2011). Pemberdayaan masyarakat di bidang kesehatan, gambaran peran kader posyandu dalam upaya penurunan angka kematian ibu dan bayi di kota Manado dan Palangkaraya. Buletin Penelitian Sistem Kesehatan, 14(2), 21269.

Rosidin, U., Eriyani, T., \& Shalahuddin, I. (2020). Pengelolaan Posyandu Citra Sebagai Upaya Peningkatan Peran Serta Masyarakat Dalam Bidang Kesehatan Di RT 04 RW 12 Desa Jayaraga Tarogong Kidul Garut. Jurnal Kreativitas Pengabdian Kepada Masyarakat (PKM), 3(2), 220-229.

Saragih, G. (2011). Motivasi Ibu Dalam Pemanfaatan Posyandu Bayi Di Desa Bangun Tobing Kecamatan STM Hilir Kabupaten Deli Serdang Tahun 2008.

Suhendar, I., Rosidin, U., \& Sumarni, N. (2020). Pendidikan Kesehatan Tentang Hidup Bersih dan Sehat di Lembaga Kesejahteraan Sosial Anak Al-Amin Garut. JPKMI (Jurnal Pengabdian Kepada Masyarakat Indonesia), 1(3), 135-145.

Suryaningsih, H. (2012). Faktor-faktor yang berhubungan dengan perilaku kunjungan ibu bayi dan balita ke posyandu di Puskesmas Kemiri Muka Kota Depok tahun 2012. Depok. Universitas Indonesia.

Widyaningsih, T. S., Windyastuti, W., \& Tamrin, T. (2020). Peran Kader Dalam Memotivasi Ibu Balita Yang Berkunjung Ke Posyandu. JKEP, 5(1), 1-12. 